\title{
Avaliação do conforto térmico no aprendizado: estudo de caso sobre influência na atenção e memória
}

\author{
Eduardo Concepción Batiz SOCIESC - IST \\ Jean Goedert SOCIESC - IST \\ Junir Junior Morsch SOCIESC - IST \\ Pedro Kasmirski Junior SOCIESC - IST \\ Rafael Venske SOCIESC - IST
}

\section{RESUMO}

O conforto térmico, cujo avaliação é um processo de caráter psicofisiológico, busca adaptar o ambiente para que este ofereça melhores condições de saúde, segurança, rendimento e bem-estar. Este artigo verifica a relação entre conforto térmico na sala de aula universitária e o rendimento da atenção e da memória dos estudantes. Métodos de avaliação objetivos e subjetivos foram aplicados nessa verificação, como o questionário baseado no modelo proposto por Batiz e Goedert, o teste das figuras de Rey e o cálculo do PMV e PPD pelas expressões de Fanger. Constatou-se uma coincidência da ordem de 90,9\% entre o PMV calculado pelas equações de Fanger e a avaliação subjetiva medida pela aplicação do questionário, demonstrando que o questionário é uma ferramenta efetiva para avaliação do conforto térmico. Constatou-se que $70 \%$ dos avaliados obtiveram resultados positivos no teste de atenção e memória. Todos os alunos que estavam em condição de conforto apresentaram resultados positivos.

\section{Evaluation of thermal comfort in learning: study case about the influence in attention and memorization}

\begin{abstract}
Thermal comfort is a psycho-physiological phenomenon that looks to environmental adaptations to provide better health conditions, and levels of safety, performance and comfort. This article examines the relationship between thermal comfort in university classrooms with students' attention and recall performance. Objective and subjective evaluation methods were applied, such as a questionnaire based on the proposed model by Batiz and Goedert, Figure of Rey Method and Fanger Method. It was observed that there is a 90.9 per cent coincidence between the PMV calculated and the subjective value measured. It shows that the questionnaire is an effective tool for evaluating thermal comfort. It was observed that 70 per cent of the students evaluated manifested a positive output in attention and memory tests. Positive results were obtained in the test by students in comfortable conditions.
\end{abstract}

\section{KEY WORDS}

Thermal comfort, attention, memory. 


\section{INTRODUÇÃO}

Todos os seres humanos apresentam respostas comportamentais e fisiológicas às variações térmicas ambientais. Ao longo da evolução humana, desde as cavernas, as primeiras vestes e o fogo até os dias atuais, com os sofisticados sistemas de climatização controlados por computadores e a utilização de lógica Fuzzy e de sensores infravermelhos, essas reações se apresentam.

Em paralelo, a investigação científica também tem se intensificado e contribuições valiosas para a compreensão dos fenômenos intrínsecos do conforto térmico têm surgido.

A busca pelo bem-estar físico, fisiológico e psicológico humano vem de longa data, porém apenas nas últimas décadas têm se intensificado os estudos dos efeitos do conforto térmico sobre as pessoas em ambientes internos (LAMBERTS; XAVIER, 2003).

As pesquisas científicas colaboraram para o estabelecimento dos princípios da avaliação da sensação térmica das pessoas em relação a um ambiente, o que possibilitou a elaboração de normas. Um dos principais trabalhos foi desenvolvido por O. Fanger, nos anos 70, o qual estabeleceu o método Prognóstico do Voto Médio (PMV), que permite prever a avaliação térmica do ambiente pelas pessoas baseado na avaliação de seis fatores: temperatura do ar, temperatura média radiante, velocidade do ar, umidade relativa do ar, vestimenta e ativida-

de (FANGER, 1970). A atual norma ISO 7730/1994 descreve o procedimento de aplicação desde método.

Outros estudos científicos têm investigado a influência da qualidade térmica do ambiente na produtividade. Uma pesquisa realizada em câmaras de teste com temperatura e umidade controladas analisou a relação entre produtividade, fadiga e estado psicológico. Seus resultados denotaram que a produtividade é maior e a fadiga desenvolve-se mais lentamente em ambiente frio do que em ambientes quentes (NELSON et al., 1987 apud SILVA, 2001).

$\mathrm{O}$ conforto térmico está relacionado à busca intuitiva do sentir-se bem natural do homem. Várias pesquisas desenvolvidas em laboratório e em campo têm verificado a relação entre o conforto térmico e o desempenho dos indivíduos (FANGER, 1970 apud SILVA, 2001).

Embora a redução da performance humana sob calor ou frio seja ainda uma questão pouco clara ou conclusiva, conforme se pode notar no estudo realizado por Woods e Winakor em uma lavanderia de um hospital nos Estados Unidos (WOODS et al., 1981), suspeita-se que a performance perceptiva, manual e intelectual é geralmente maior na presença de conforto térmico (XAVIER, 1999).
Nos anos 1960 e 1970, vários estudos científicos analisaram a influência do ambiente térmico no desempenho escolar de alunos. Trabalhos como os de Wyon, Wargocki e Krogstad relatam que o aumento da temperatura e a qualidade do ar reduzem a performance do aprendizado (WARGOCKI et al., 2005). Em 2002, baseado em um levantamento bibliográfico realizado em 21 estudos científicos (MENDELL; HEATH, 2005), Mendell conclui que o ambiente térmico influencia o aprendizado.

Contudo ainda existem pontos que podem ser investigados. Muitos desses estudos realizados basearam-se somente na variável temperatura do ar para avaliar o desempenho na aprendizagem. A utilização de todas as variáveis térmicas estabelecidas por Fanger em estudos científicos que avaliam o desempenho do aprendizado é rara.

Então é necessário verificar o quanto as variáveis ambientais influenciam no conforto e no rendimento do trabalho ou numa atividade realizada por um grupo de pessoas. Manifestações fisiológicas como dor de cabeça, fadiga, alteração sensorial, depressão intelectual, indiferença, sono, descoordenação motora e perda de memória têm surgido cada vez mais frequentemente.

A ASHRAE (American Society of Heating, Refrigeration and Ar Conditioning Engineers) define conforto térmico

\section{aumento da temperatura e a qualidade do ar reduzem a performance do aprendizado.}

como a condição da mente na qual o indivíduo expressa satisfação com o ambiente térmico (ASHRAE Standard 55, 1992 apud ASHRAE, 2001).

A avaliação do conforto térmico é um processo cognitivo que envolve muitos dados influenciados por aspectos físicos, fisiológicos, psicológicos e outros (ASHRAE, 2001).

Há variáveis psicológicas tão ou mais significativas do que as padronizadas a serem levadas em consideração nos estudos do conforto térmico: temperatura percebida pela pessoa, sensação de estar mais aquecida ou mais refrescada do que outras pessoas, tolerância percebida ou tolerabilidade, ajustamento ou adaptação. Além dessas quatro, apontam os autores ainda quatro outras variáveis psicológicas consequentes, as quais são indício da tolerância percebida: decréscimo de performance, decréscimo de conforto, decréscimo de energia física e decréscimo de afeto (HOWELL; STRAMLER, 1981 apud XAVIER, 1999).

Segundo a psicologia, o processo de avaliação do conforto térmico é elucidado pelos conceitos de sensação e percepção.

A sensação é um fato psicofisiológico provocado pela excitação de um órgão sensorial (FOLQUIE, 1952 
apud SANTOS, 1967). Por causa de sua correlação fisiológica-psicológica tal reação não é somente um processo psicológico.

O fenômeno da sensação decorre de três condições fundamentais (SANTOS, 1967):

- Excitação: de natureza física, é o elemento provocador que age sobre o órgão sensorial. No caso do conforto térmico, se enquadrariam como elementos provocadores os mecanismos de intercâmbio térmico entre o meio e o indivíduo (convecção, condução, radiação e evaporação).

- Impressão: de natureza fisiológica, são as modificações registradas pelos órgãos sensoriais que são transmitidas ao cérebro por fibras nervosas.

- Sensação: de natureza psicológica, é o estado de consciência resultante dos processos de excitação e impressão. A sensação pode ser distinguida ainda em duas linhas: as que nos dão noção de qualidade ou de um estado (frio ou calor) e as que determinam o conhecimento de um objeto determinado, a qual se denomina percepção (vento forte esfria, por exemplo).

A percepção tem um papel importante na vida diária do ser humano, pois é por meio dela que o indivíduo atribui significados às coisas, ações e feitos. Rodriguez e Delgado (1998) descrevem o processo de percepção como a atribuição de significado a estímulos internos (fome, sede etc.) e externos (frio, calor etc.). Somente os estímulos aos quais os indivíduos prestam atenção são selecionados e fragmentados para posteriormente serem remontados mentalmente como um quebra-cabeça (significado). O significado atribuído está sob influência de fatores externos (pressão do grupo, interação e grupos de referência) e fatores internos (objetivos, necessidades, valores e experiência prévia). Também é importante ressaltar que a percepção varia para cada indivíduo, sendo para cada um uma verdade que só se modifica com dados que comprovem o contrário.

A atenção é um processo mental que permite que as pessoas se centrem em um determinado estímulo ou informação relevante. Podem-se distinguir diferentes tipos de atenção. A atenção focalizada implica concentrar-se em um determinado estímulo; a atenção seletiva requer a concentração em um estímulo ou informação e a inibição das respostas a outros estímulos que possam distrair; a atenção mantida ou sustenida consiste na persistência e na manutenção da atenção durante a execução de uma tarefa. A atenção é um pré-requisito para o funcionamento de processos cognitivos mais complexos, já que não é possível avaliar a percepção, a memória ou qualquer outra atividade mental sem considerar os processos de atenção (CAMPOS; SANTACANA; NEBOT, 2008).

A mesma fonte destaca que os procedimentos básicos utilizados para avaliar a memória são três: o reconhecimento, a lembrança livre e a lembrança com clave (código). Em uma tarefa de reconhecimento mostram-se à pessoa avaliada uma série de objetos, desenhos ou palavras que, posteriormente, ela deve identificar entre várias alternativas a ela apresentadas. Nas tarefas que avaliam a lembrança livre é apresentada uma série de estímulos e a pessoa deve reproduzi-los, depois da apresentação, na ordem que prefirir. Finalmente, na lembrança com claves apresenta-se uma série de pistas ou sinais que têm algum tipo de relação com a informação que precisa ser lembrada e que servem para dirigir e facilitar o processo de recuperação da informação.

O presente artigo tem como objetivo geral estimar a performance da atenção e memória de estudantes univer-

\section{atenção é um pré-requisito para o funcionamento de nitivos mais complexos.}

sitários sob variações térmicas, avaliada pelo método de Fanger.

\section{MATERIAIS E MÉTODOS}

\subsection{População e amostra}

Foram estudados 75 estudantes que integram duas turmas do Instituto Superior Tupy - IST, da Sociedade Educacional de Santa Catarina - SOCIESC, na cidade de Joinville, SC.

Da população total de ambas as turmas (75 alunos) foram estudados de forma voluntária 64 estudantes, o que representa $85,3 \%$ do total. Uma das turmas compunha-se de 22 estudantes de graduação da $6{ }^{a}$ fase da especialidade Tecnologia de Qualidade Produtividade, dos quais 18 eram homens e 4 eram mulheres; a outra turma era de pós-graduação, integrada por 42 estudantes, 33 homens e 9 mulheres. Do total de 64 alunos que formaram a amostra estudada, então, 51 eram homens e 13 eram mulheres. A distribuição da amostra por faixa etária está representada na Figura 1.

Na Figura 1 observa-se que a maior concentração de alunos participantes da amostra está na faixa etária entre 21 e 30 anos (39), os quais representam $60,9 \%$ do total, seguida pela faixa entre 31 e 40 anos (15), que representa 


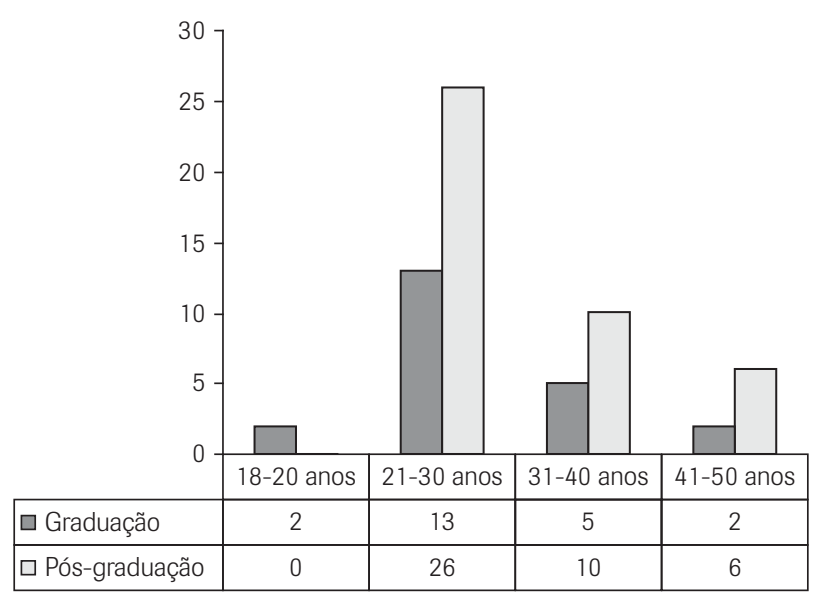

Figura 1: Distribuição da amostra por faixa etária.

$23,4 \%$. Considerando que $87,5 \%$ desses estudantes tinham entre 18 e 40 anos, destaca-se que a amostra é jovem e representativa para o estudo do conforto térmico entre universitários por representar as faixas etárias mais comuns entre eles.

\subsection{Procedimentos de estudo}

Para cumprir com o objetivo proposto na pesquisa, os autores dividiram o trabalho em várias etapas. Numa primeira etapa foi realizado um estudo sobre os diferentes fatores que influenciam o conforto térmico do ser humano e a forma como o organismo humano a eles reage, sendo alguns deles discutidos no presente artigo.

Numa segunda etapa da pesquisa foram estudados os diferentes modelos de avaliação do conforto térmico que existem e as variáveis e fatores considerados para avaliar essa importante condição que afeta o ser humano e, mais especificamente, os estudantes universitários em sala de aula.

Diferentes tipos de índices e modelos têm sido adotados na avaliação do conforto térmico, principalmente na construção civil. Provavelmente, o método mais conhecido e aceito é o desenvolvido por Fanger e adotado por normas internacionais (ISO7730/1994; ISO7730/2005) e pela ASHRAE (2001). Fanger realizou pesquisas com populações na Dinamarca e nos EUA, controlando as condições de temperatura, umidade e velocidade de ar em câmaras climáticas, nas quais as pessoas permaneciam algum tempo antes de responder a questionários sobre sua percepção do ambiente térmico. Desses estudos surgiram equações sobre as trocas de calor entre o homem e o ambiente que, em teoria, representam as respostas do individuo ao estado de conforto térmico. São considerados parâmetros individuais (roupa, atividade etc.) e parâmetros físicos do ambiente (temperatura do ar, temperatura média radiante, velocidade do ar e umidade do ar).

Outros índices e modelos de importância são aqueles com abordagem adaptativa desenvolvidos por Humphreys, Nicol e Mahoney. Esses índices têm sido tema de muitos trabalhos científicos e pesquisas de âmbito nacional têm encontrado divergências entre os modelos apresentados nas normas e a preferência das pessoas (GOUVEA et al., 2003).

Questiona-se se modelos aplicados em condições de laboratório, nas quais o indivíduo não está exercendo sua atividade, ou seja, não tem um histórico com os componentes acima destacados, podem ser aplicados na avaliação de um ambiente de trabalho (GOEDERT; BATIZ, 2004; BATIZ; GOEDERT, 2006).

Numa terceira etapa da pesquisa foi aplicado um modelo desenhado por Batiz e Goedert (2006), avaliando-se que este modelo era muito simples e apresentava boa aplicabilidade aos fatores físicos do ambiente de trabalho.

O modelo proposto por Batiz e Goedert (2006) se baseia no fato de que as sensações percebidas pelos seres humanos permitem avaliar de forma exata como as condições físicas na área analisada influem no conforto térmico.

A Figura 2 apresenta em síntese o processo de avaliação do conforto térmico proposto por Batiz e Goedert. Nesse processo podem-se destacar, além das condições físicas do ambiente (natureza física) e do metabolismo (natureza fisiológica), componentes relacionados ao processo cognitivo como: experiência prévia, objetivos, necessidades e interação, os quais influenciam na atribuição de significado.

A proposta do modelo baseia-se na elaboração de um questionário subjetivo (BATIZ; GOEDERT, 2006) que deverá ser preenchido pelos estudantes que participam da análise (Figura 3). A elaboração do questionário seguiu as especificações da norma ISO10551/1995.

Como se observa na Figura 3, o questionário se encontra dividido em duas partes:

- Na primeira parte do questionário foram relacionados dados considerados importantes e que influenciam na questão do conforto térmico; estes dados poderão ser utilizados na avaliação do conforto individual e de grupo. Entre os dados a serem preenchidos nesta primeira parte encontravam-se: nome, localização da carteira do aluno, peso em kg, estatura em $\mathrm{m}$, idade, sexo, vestimenta, descrição da última refeição (na hora anterior às medições), meio de transporte utilizado para se locomover até o lugar aonde foram realizadas as medições (na hora anterior às medições) e sobre a saúde do entrevistado. 


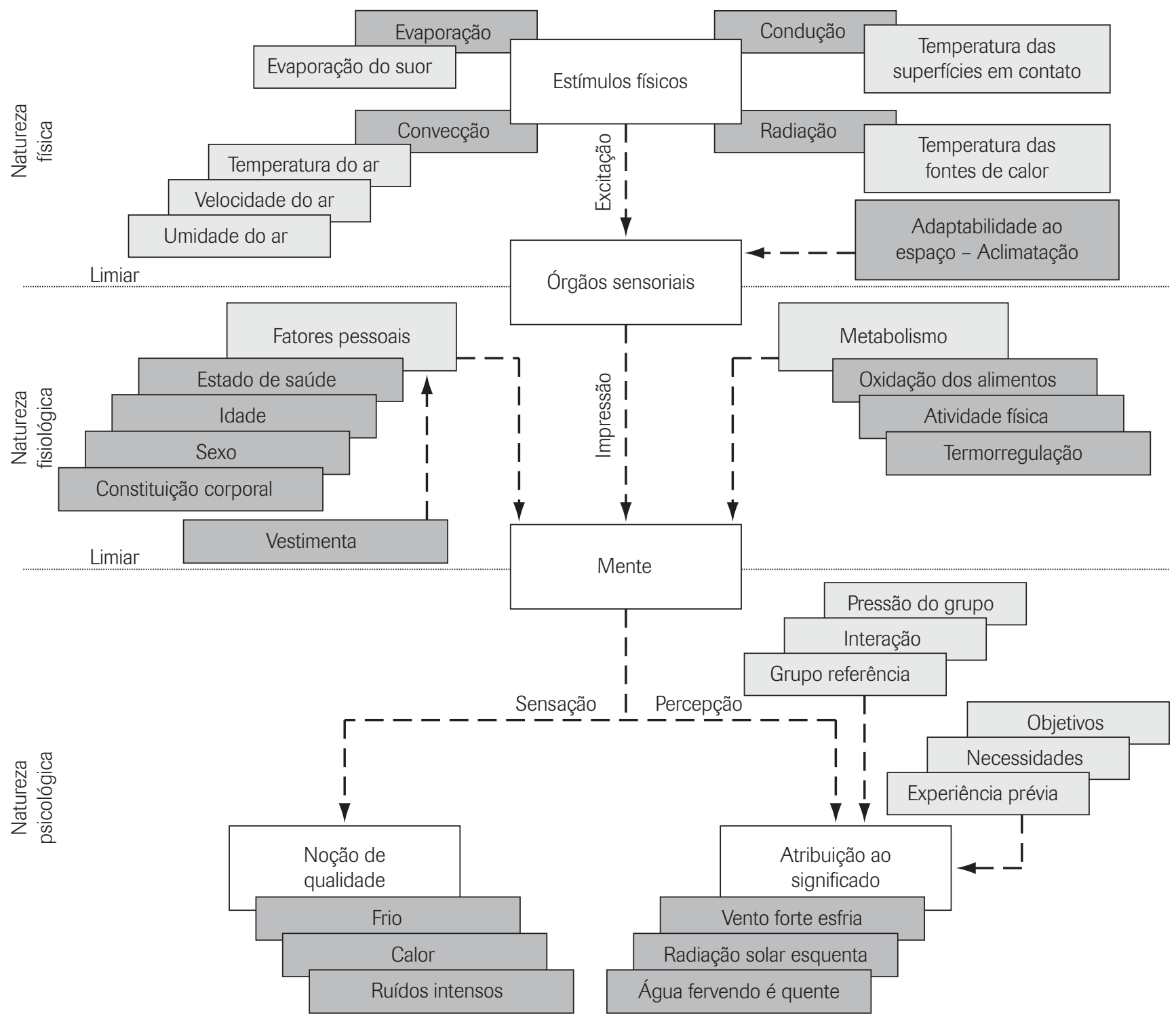

Figura 2: Processo de avaliação do conforto térmico. Fonte: BATIZ e GOEDDERT (2006)

- Na segunda parte do questionário foram formuladas três questões nos âmbitos de percepção, estimativa e preferência térmica e uma questão sobre avaliação do ambiente térmico:

- No âmbito da percepção, o questionamento referiuse ao estado térmico em que a pessoa se encontrava naquele momento. A pergunta realizada foi: "como você se sente agora?" As opções de resposta disponíveis foram apresentadas em uma escala de sete graus de intensidade, os mesmos estabelecidos por Fanger no cálculo de PMV: com muito calor; com calor; com pouco calor; nem com calor, nem com frio (neutro); com pouco frio; com frio; com muito frio.

- No âmbito estimativo, relacionado à condição em que o indivíduo se encontrava naquele momento, a pergunta realizada foi "como está o ambiente térmico junto a você agora?” As opções para resposta disponíveis foram apresentadas em uma escala com cinco graus de intensidade: extremamente 
Avaliação do conforto térmico

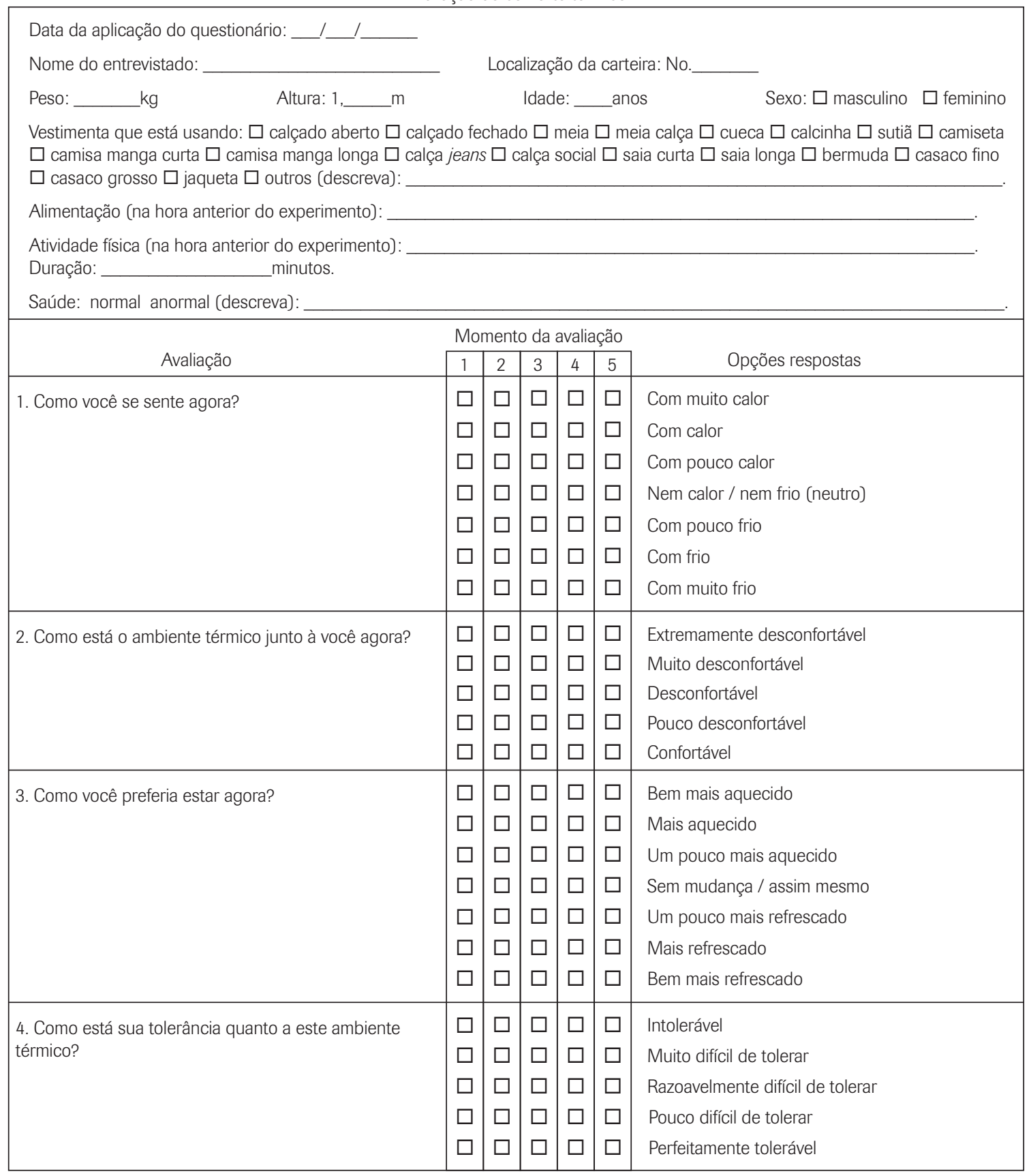

SUA OPINIÃO É MUITO IMPORTANTE PARA NÓS, OBRIGADO!

Legenda: Momento da avaliação:

\begin{tabular}{|c|c|}
\hline 1. __ hora(s) e___ minuto(s) & 4.__ hora(s) e___ minuto(s) \\
\hline 2. __ hora(s) e__ minuto(s) & 5. __ hora(s) e__ minuto(s) \\
\hline 3. __ hora(s) e __ minuto(s) & \\
\hline
\end{tabular}

Figura 3: Questionário de avaliação subjetiva do conforto térmico.

Fonte: BATIZ e GOEDERT (2006) 
desconfortável; muito desconfortável; desconfortável; pouco desconfortável; confortável.

- No âmbito preferência, avaliou-se a preferência térmica do indivíduo naquele momento. A pergunta realizada foi "como você preferia estar agora?" As respostas disponíveis foram apresentadas em uma escala de sete graus de intensidade: bem mais aquecido; mais aquecido; um pouco mais aquecido; sem mudança, assim mesmo; um pouco mais refrescado; mais refrescado; bem mais refrescado.

- Foi formulada uma questão que tinha por finalidade avaliar a opinião do entrevistado em relação ao ambiente térmico.

- Trata-se da tolerância do entrevistado em relação à condição térmica do ambiente. A pergunta realizada foi "como está sua tolerância quanto a este ambiente térmico?" As opções de resposta foram apresentadas numa escala de cinco graus de intensidade: intolerável; muito difícil de tolerar; razoavelmente difícil de tolerar; pouco difícil de tolerar; perfeitamente tolerável.

Em uma quarta etapa foi aplicado o questionário de avaliação subjetiva e foram realizadas medições de temperatura do $\operatorname{ar}\left({ }^{\circ} \mathrm{C}\right)$, velocidade do ar $(\mathrm{m} / \mathrm{s})$, umidade relativa (\%) e temperatura de globo $\left({ }^{\circ} \mathrm{C}\right)$, segundo o estabelecido na ISO 7726 (1998) com o objetivo de calcular o PMV (Voto Médio Previsível) e PPD (Porcentagem de Pessoas Insatisfeitas), a fim de comparar os valores desses dois indicadores de conforto térmico com os resultados do questionário.

Em uma quinta etapa foram avaliadas a atenção e a memória dos entrevistados com a aplicação do teste Figuras complexas de Rey (1999). Esta técnica foi aplicada para verificar qual índice de atenção e de memória o acadêmico apresentava.

O experimento foi realizado da seguinte forma: antes de sua aplicação, os estudantes foram treinados, fizeram simulações de preenchimento das diferentes técnicas a serem aplicadas, assim como foram alertados com relação ao momento do preenchimento e da necessidade de que todos os instrumentos fossem preenchidos individualmente.

Quando o estudante entrava na sala de aula em que se realizava o experimento, a temperatura ambiente estava controlada pelos pesquisadores, o que não era do conhecimento dos alunos participantes. Vale ressaltar que as salas de aula tinham equipamento de ar condicionado. A partir da entrada dos estudantes, a saída da sala de aula foi proibida, para evitar mudanças bruscas nas condições ambientais.

Depois de 30 minutos de permanência dos estudantes na sala de aula e de eles estarem aclimatados às condições a que estavam expostos, foi realizada a primeira medição, que consistiu em eles responderem as quatro perguntas, escolhendo uma alternativa para cada uma, e foram realizadas as medições das variáveis climáticas $\left(\mathrm{t}_{\mathrm{a}}, \mathrm{UR}, \mathrm{V}_{\mathrm{a}}\right)$ em seis pontos representativos da sala de aula (pontos onde havia concentração de estudantes). Essa operação foi repetida em cinco ocasiões, com intervalos de 20 minutos.

Depois de terminada a terceira medição do dia, foi respondida a seguinte pergunta:

Em sua opinião, como deveria estar o ambiente térmico para seu melhor desempenho acadêmico?

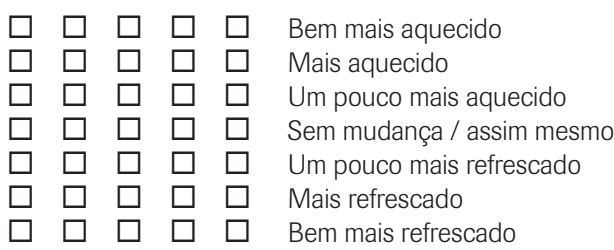

Depois da última medição e de o professor haver ministrado todo o conteúdo da aula foi aplicado o teste de Rey.

$\mathrm{O}$ teste consistiu em, primeiramente, $\mathrm{o}$ aluno copiar em uma folha a figura apresentada em um slide, sendo necessário observar as proporções e, sobretudo, não se esquecer de nenhum dos elementos que a compunham. Nesta etapa estava se avaliando o processo de atenção, ou seja, a capacidade de reproduzir uma figura complexa com auxílio de slide para visualização. Em uma segunda etapa, o estudante teve que reproduzir a figura sem o auxílio do slide, com o que se avaliou o processo de memória.

Em um primeiro momento foi aplicado o teste (Figura 4) que mostra a divisão da figura em 11 unidades.

Posteriormente e em três momentos diferentes (três medições diferentes), com exposição dos estudantes a parâmetros ambientais diferentes, foi aplicado um teste mais complexo (Figura 5), o qual apresenta a figura dividida em 18 unidades.

O experimento foi repetido durante cinco dias com os mesmos procedimentos e com o mesmo professor ministrando conteúdos diferentes. Posteriormente foram calculados os índices PMV e PPD levando em consideração

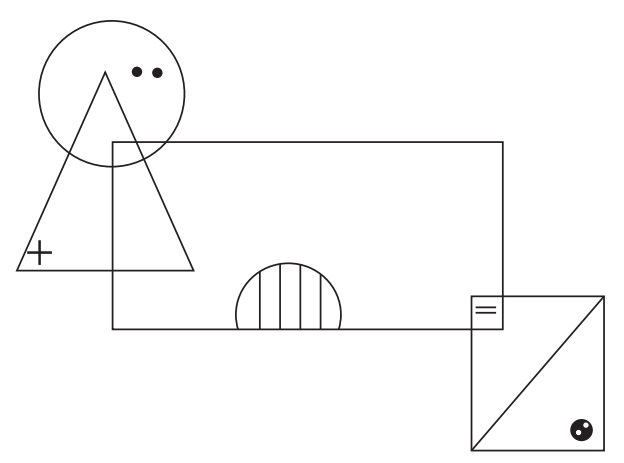

Figura 4: Figura do teste de Rey. Fonte: Rey (1999) 


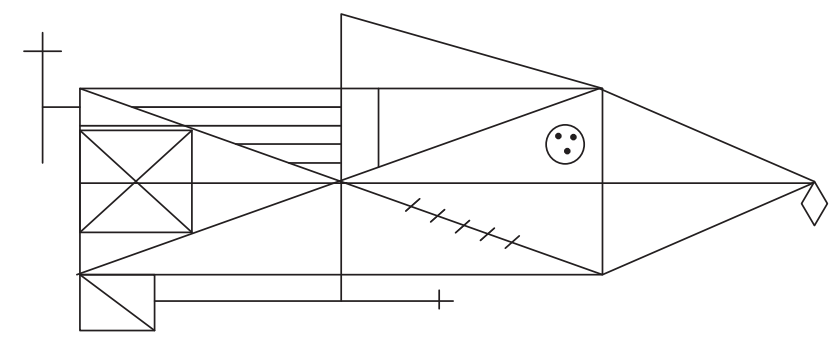

Figura 5: Figura do teste de Rey. Fonte: Rey (1999)

os resultados das medições das variáveis ambientais e dos dados individuais e analisados os resultados dos questionários e dos testes com as figuras de Rey.

\section{RESULTADOS E DISCUSSÃO}

A temperatura do ar medida em diferentes pontos da sala de aula variou entre um mínimo de $18,4^{\circ} \mathrm{C}$ e um máximo de $20,6^{\circ} \mathrm{C}$. Essa variação se deveu fundamentalmente às características das salas de aula e à localização do aparelho de ar condicionado. Os resultados obtidos foram:

- Na primeira coleta de dados, $65 \%$ dos alunos estavam satisfeitos com o ambiente e 35\%, insatisfeitos. É importante destacar que, do total de insatisfeitos, quatro eram mulheres, que durante todo o experimento demonstraram ser muito mais sensíveis a baixas temperaturas do que os homens, além de frequentemente usarem pouca vestimenta e sentirem frio localizado principalmente nos braços e pernas. Houve coincidência de $95,4 \%$ entre os critérios do PMV calculado e os do subjetivo.

- Na segunda coleta de dados, $40 \%$ estavam satisfeitos com o ambiente e $60 \%$, insatisfeitos. Houve coincidência de $90,9 \%$ com relação ao PMV calculado, conforme comparação dos dados das variáveis ambientais e pessoais com os do PMV subjetivo, determinado pelas respostas dos alunos ao questionário.

- Os resultados da terceira medição foram similares aos da primeira, ou seja, quatro pessoas estavam insatisfeitas com o ambiente e três delas eram mulheres, as quais, quando consultadas, apontaram como causa da insatisfação serem pessoas normalmente susceptíveis ao frio.

- Os resultados da quarta e quinta medições mostraram que $77 \%$ da amostra estavam satisfeitos com o ambiente, ressaltando-se novamente que a vestimenta usada pelas mulheres não era apropriada.
Um aspecto que influiu na sala de aula e foi motivo de queixas dos estudantes, sobretudo daqueles que não estavam satisfeitos, foi a velocidade do ar, que em alguns pontos era alta. Da mesma forma, as diferenças individuais, a alimentação e a intensidade das atividades que eles realizavam e cujo gasto energético era baixo foram fatores importantes a considerar para a avaliação do conforto térmico.

Para entender melhor quando se fala de compatibilidade entre o PMV calculado e o subjetivo estimado pelo questionário mostra-se, na Tabela 1 , um exemplo de um aluno durante o primeiro dia de medição.

O PMV desenvolvido por Fanger, correspondente ao valor médio previsto dos votos com relação à sensação térmica que um grupo de pessoas experimentaria em uma determinada situação, numa escala subjetiva de sete pontos:

\begin{tabular}{|c|c|c|c|c|c|c|}
\hline-3 & -2 & -1 & 0 & +1 & +2 & +3 \\
\hline $\begin{array}{c}\text { Muito } \\
\text { frio }\end{array}$ & Frio & $\begin{array}{c}\text { Ligeiramente } \\
\text { frio }\end{array}$ & Neutro & $\begin{array}{c}\text { Ligeiramente } \\
\text { quente }\end{array}$ & Quente & $\begin{array}{c}\text { Muito } \\
\text { quente }\end{array}$ \\
\hline \\
Desconforto por frio
\end{tabular}

Quando calculados os valores de PMV segundo a expressão de Fanger se observa que as condições mostram que o ambiente a que está exposto o estudante utilizado como exemplo apresenta desconforto por frio $(-1,1$, ou seja, ligeiramente frio ou com pouco frio). Esta situação coincide com a resposta dele ante esse ambiente, em que manifestou sentir desconforto por frio (PMV subjetivo estimado igual a -1 , ou seja, com pouco frio). Dessa forma, o aluno demonstrou, durante todo o experimento, compatibilidade com a situação ambiental na sala de aula.

Para ilustrar a aplicação do questionário subjetivo à amostra selecionada apresentamos a seguir os resultados obtidos durante um dos dias de medições (Figura 6 e Tabela 2) de três dos alunos participantes da segunda coleta de dados, onde existiu uma coincidência de $90,9 \%$ entre o PMV calculado e o PMV subjetivo.

Na Figura 6 e na Tabela 2 se observa, por exemplo, que os resultados obtidos com a aplicação da equação de Fanger, no

\section{Tabela 1: Exemplo da compatibilidade entre o PMV calculado segundo as expressões de Fanger e o PMV estimado ou subjetivo, avaliado pelo preenchimento do questionário.}

\begin{tabular}{ccc}
\hline Medição & PMV calculado & PMV subjetivo \\
\hline 1 & $-1,1$ & $-1,0$ \\
2 & $-1,1$ & $-1,0$ \\
3 & $-1,1$ & $-1,0$ \\
4 & $-1,1$ & $-1,0$ \\
5 & $-1,1$ & $-1,0$ \\
\hline
\end{tabular}


caso do terceiro aluno, foram muito similares aos resultados obtidos com a aplicação do questionário subjetivo (tanto os valores do PMV calculado quanto do PMV subjetivo estão na zona de conforto, bem perto do valor neutro), ao longo das cinco medições realizadas. No caso do segundo aluno, os resultados também foram similares, dentro da zona de conforto, exceto por um valor de um estudante que ultrapassou essa zona e ficou com um pouco de frio.

Para o primeiro aluno ocorreram quatro valores que não coincidiram com os do PMV subjetivo, porém quando entrevistado ele manifestou que era uma pessoa com maior inclinação de satisfação com o frio e que por isso sua reação era sentir-se confortável na situação - ressalte-se que a diferença entre o que seria conforto e os valores calculados foi muito pequena.

No caso dos estudantes de pós-graduação, os resultados foram similares aos obtidos com os estudantes de graduação, como mostra a Tabela 3.

Analisando-se a Tabela 3 se observa que os três estudantes estão em concordância com os valores do PMV calculado. Para o aluno n. ${ }^{\circ} 1$, os valores de PMV calculados estão dentro do intervalo aceito por Fanger como de conforto térmico (de $-0,5$ até $+0,5$ ) e sua resposta subjetiva foi neutra (sem frio nem calor). Igual situação ocorreu com o segundo aluno. Já no caso do terceiro só aconteceu uma não concordância, no último valor, onde o PMV calculado denota que não há conforto mas um pouco de frio e resposta dele foi "conforto térmico". Neste caso específico é importante ressaltar que o valor calculado está muito próximo do limite e, portanto, fica muito difícil para as pessoas diferenciarem entre conforto ou desconforto térmico.

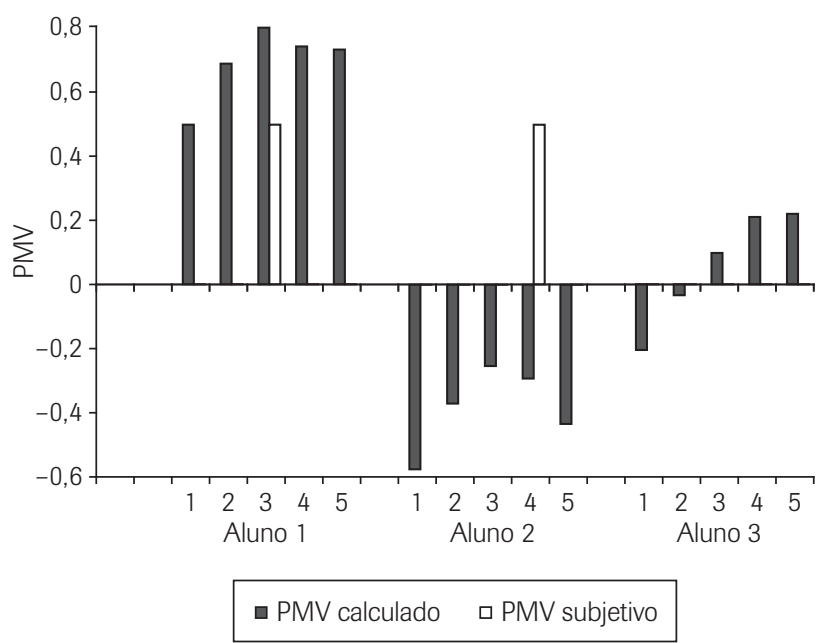

Figura 6: Exemplo dos resultados obtidos na coleta de dados.
Com relação à turma, existiu uma concordância entre o PMV calculado e o subjetivo em 88,1\% (37 de 42) dos casos. Os cinco alunos para os quais não ocorreram concordância foram três mulheres e dois homens que manifestaram alta

Tabela 2: Exemplo dos resultados obtidos com o PMV e o PPD calculados pelas expressões de Fanger e o PMV subjetivo junto a estudantes de graduação.

\begin{tabular}{cccccc}
\hline Medição & Aluno & $\begin{array}{c}\text { Horário } \\
\text { medição }\end{array}$ & $\begin{array}{c}\text { PMV } \\
\text { calculado }\end{array}$ & $\begin{array}{c}\text { PPD } \\
\text { calculado } \\
\text { (\%) }\end{array}$ & $\begin{array}{c}\text { PMV } \\
\text { subjetivo }\end{array}$ \\
\hline 1 & I & $20 \mathrm{~h} 50$ & 0,5 & 12 & 0 \\
2 & I & $21 \mathrm{~h} 10$ & 0,69 & 20,91 & 0 \\
3 & I & $21 \mathrm{~h} 30$ & 0,8 & 27,97 & 0,5 \\
4 & I & $21 \mathrm{~h} 50$ & 0,74 & 23,89 & 0 \\
5 & I & $22 \mathrm{~h} 10$ & 0,73 & 22,86 & 0 \\
1 & II & $20 \mathrm{~h} 50$ & $-0,57$ & 14,38 & 0 \\
2 & II & $21 \mathrm{~h} 10$ & $-0,37$ & 7,76 & 0 \\
3 & II & $21 \mathrm{~h} 30$ & $-0,25$ & 6,39 & 0 \\
4 & II & $21 \mathrm{~h} 50$ & $-0,29$ & 6,92 & 0,5 \\
5 & II & $22 \mathrm{~h} 10$ & $-0,43$ & 9,86 & 0 \\
1 & III & $20 \mathrm{~h} 50$ & $-0,2$ & 5,91 & 0 \\
2 & III & $21 \mathrm{~h} 10$ & $-0,03$ & 5,01 & 0 \\
3 & III & $21 \mathrm{~h} 30$ & 0,1 & 5,2 & 0 \\
4 & III & $21 \mathrm{~h} 50$ & 0,21 & 5,94 & 0 \\
5 & III & $22 \mathrm{~h} 10$ & 0,22 & 6,05 & 0 \\
\hline
\end{tabular}

Tabela 3: Exemplo dos resultados obtidos com o PMV e o PPD calculados pelas expressões de Fanger e o PMV subjetivo obtido junto a estudantes de pós-graduação.

\begin{tabular}{lccccc}
\hline Medição & Aluno & $\begin{array}{c}\text { Horário } \\
\text { medição }\end{array}$ & $\begin{array}{c}\text { PMV } \\
\text { calculado }\end{array}$ & $\begin{array}{c}\text { PPD } \\
\text { calculado }\end{array}$ & $\begin{array}{c}\text { PMV } \\
\text { subjetivo }\end{array}$
\end{tabular}
(\%)

\begin{tabular}{rrrrrr}
\hline 1 & I & $11 \mathrm{~h} 20$ & $-0,20$ & 5,84 & 0 \\
2 & I & $11 \mathrm{~h} 40$ & $-0,29$ & 6,94 & 0 \\
3 & I & $12 \mathrm{~h} 00$ & $-0,30$ & 7,13 & 0 \\
4 & I & $12 \mathrm{~h} 20$ & $-0,21$ & 5,98 & 0 \\
5 & I & $12 \mathrm{~h} 40$ & $-0,37$ & 8,45 & 0 \\
1 & II & $11 \mathrm{~h} 20$ & $-0,13$ & 5,36 & 0 \\
2 & II & $11 \mathrm{~h} 40$ & $-0,05$ & 5,06 & 0 \\
3 & II & $12 \mathrm{~h} 00$ & $-0,14$ & 5,40 & 0 \\
4 & II & $12 \mathrm{~h} 20$ & $-0,15$ & 5,45 & 0 \\
5 & II & $12 \mathrm{~h} 40$ & $-0,19$ & 5,79 & 0 \\
1 & III & $11 \mathrm{~h} 20$ & $-0,67$ & 19,32 & -1 \\
2 & III & $11 \mathrm{~h} 40$ & $-0,60$ & 16,03 & -1 \\
3 & III & $12 \mathrm{~h} 00$ & $-0,50$ & 11,83 & -1 \\
4 & III & $12 \mathrm{~h} 20$ & $-0,64$ & 17,80 & -1 \\
5 & III & $12 \mathrm{~h} 40$ & $-0,62$ & 16,63 & 0 \\
\hline
\end{tabular}


sensibilidade ao frio e, sobretudo, ao frio localizado em mãos e pés.

É importante destacar que, como foi dito anteriormente, houve coincidência superior a $90 \%$ entre PMV e PPD calculados e as respostas dos alunos. Isto permitiu concluir que o modelo desenhado para a avaliação do conforto térmico pelos pesquisadores Batiz e Goedert e o questionário subjetivo são instrumentos que podem ser utilizados para avaliação do conforto térmico.

Corgnati realizou experimentos similares em 2002, verificando que $90 \%$ dos estudantes estavam satisfeitos e que apenas $10 \%$ consideravam o ambiente termicamente desconfortável (STEFANO et al., 2008).

A análise dos resultados obtidos junto à turma de graduação durante os testes de atenção e memória, através da aplicação do teste das figuras de Rey, são apresentados na Tabela 4.

Na Tabela 4 pode-se observar que os resultados obtidos pelos alunos no teste de percepção com a utilização das figuras de Rey foram satisfatórios, já que a menor porcentagem obtida de nível bom e muito bom foi $86 \%$; nas medições restantes, os valores ultrapassaram $92 \%$. É interessante discutir como os resultados da aplicação da segunda figura de Rey (Figura 5), que é mais complexa do que a primeira, foram superiores - a explicação seria que, segundo os próprios estudantes, eles estavam mais preparados para enfrentar esse tipo de teste, porém os resultados não foram significativamente diferentes.

No caso do processo de avaliação da memória, os resultados também foram satisfatórios, porém inferiores aos de percepção, porque neste caso eles deveriam memorizar a figura e transferi-la para uma folha.

Para maior compreensão do que está sendo discutido, na Figura 7 se mostra um exemplo dos resultados obtidos por seis estudantes, durante a aplicação do teste de percepção e memória, ao longo da primeira medição.

Na primeira medição, com a exceção de uma aluna cuja porcentagem de acertos foi inferior a sete $(6,82$, pontuação regular), os restantes tiveram desempenho muito bom no teste de percepção. No caso do teste de memória, a situação foi diferente devido a seis acadêmicos terem obtido média

Tabela 4: Resultados da aplicação do teste de Rey na turma de graduação.

\begin{tabular}{cccccc}
\hline \multirow{2}{*}{ Processo } & \multicolumn{5}{c}{ Porcentagem de bom e ótimo no teste de Rey } \\
\cline { 2 - 6 } & $1^{\mathrm{a}}$ & $2^{\mathrm{a}}$ & $3^{\mathrm{a}}$ & $4^{\mathrm{a}}$ & $5^{\mathrm{a}}$ \\
\cline { 2 - 6 } & 92,86 & 86,0 & 92,86 & 94,0 & 94,0 \\
\hline Percepção & 71,0 & 85,71 & 56,0 & 71,0 \\
\hline
\end{tabular}

inferior a sete (quatro com pontuação regular e dois com pontuação insatisfatória).

Na segunda medição, apresentou-se uma situação parecida, porém foi utilizada a Figura 5, de Rey, que tem um grau de complexidade maior. Nota-se que a porcentagem de acertos no teste de percepção foi 6,86\% inferior à da primeira medição, porém com relação ao teste de memória a porcentagem foi quase $17 \%$ superior. No teste de percepção, só três estudantes ficaram com média inferior a sete (todos com pontuação regular), já no de memória foram seis (dois com pontuação de regular, dois satisfatórios e dois insatisfatórios).

Os resultados da terceira medição foram muito similares aos anteriores com relação ao processo de percepção. Observa-se que a porcentagem de bom e ótimo nesta fase foi de 92,86\%, valor idêntico à primeira medição, e 6,86\% superior à segunda medição - só um estudante teve média inferior a sete (a pontuação obtida foi regular). Na avaliação da memória se observa que nesta ocasião a porcentagem de bom e ótimo foi muito alta $(85,71 \%)$ e que só dois estudantes tiveram desempenho menor que a média sete, ambos avaliados como regular.

$\mathrm{Na}$ quarta fase, a média com relação às porcentagem de bom e ótimo para o processo de percepção se manteve, com um total de $94 \%$, mas com só um aluno com média inferior a sete (a pontuação obtida foi regular), embora os resultados do teste de memória tenham sido os piores obtidos, com uma porcentagem de bom e ótimo de $56 \%$ e oito alunos com média menor que sete (seis regulares; um satisfatório e um insatisfatório).

$\mathrm{Na}$ última medição, a mesma situação do teste de percepção da quarta se manteve, $94 \%$ de ótimo e bom, com

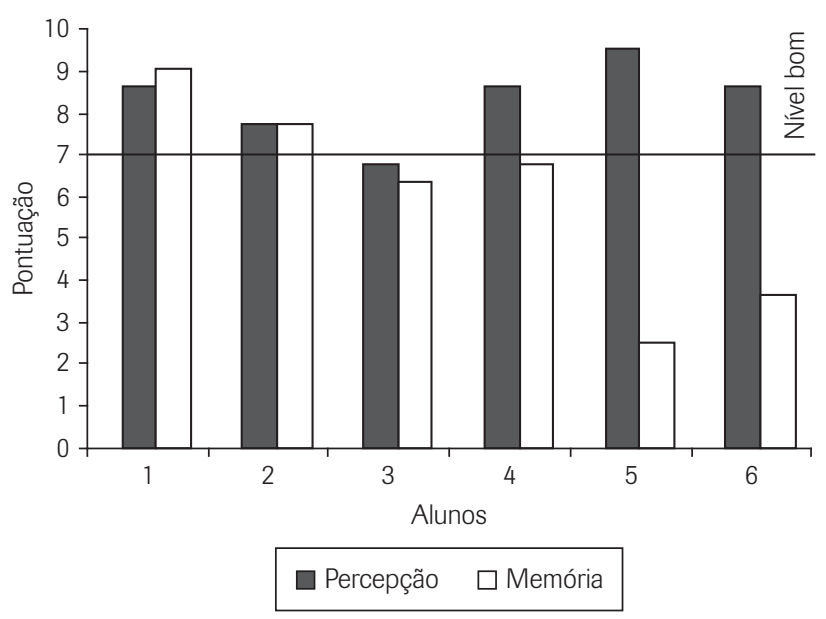

Figura 7: Resultados da aplicação do teste de atenção e memória durante a primeira medição. 
só um aluno com média inferior a sete (pontuação regular) e $71 \%$ de ótimo e bom no teste de memória, com seis alunos com média inferior a sete (todos com pontuação regular).

Os alunos manifestaram que as condições térmicas da sala influiam na percepção e na memória. Quando as condições reconhecidas por eles foram de conforto, houve um ambiente melhor para a obtenção de resultados positivos no processo e quando essas condições foram de desconforto houv mais opção pelas condições de frio, porém as mulheres continuam preferindo as condições mais quentes.

Em 2004, Wargocki realizou um experimento com alunos de 6 a 16 anos verificando que a redução da temperatura aumentava a velocidade de resposta em $28 \%$, reduzia os erros de atenção em $10 \%$ e aumentava em $24 \%$ o ritmo na leitura de textos (WARGOCKI et al., 2005).

Pode-se concluir que o ambiente térmico entre $18^{\circ} \mathrm{C}$ e $26^{\circ} \mathrm{C}$ não prejudicou a atenção e a memória dos acadêmicos, ou seja, colaborou para que os alunos não sofressem os efeitos psicológicos, permitindo terem uma boa atuação em sala de aula. Em geral, obteve-se média de desempenho de $70 \%$ nos testes de atenção e memória, durante os dias em que foram realizados os experimentos.

\section{CONCLUSÕES}

Ficou evidente, no presente trabalho, que o estudo do conforto térmico e sua relação com o processo de atenção e memória são de extrema importância. Verificou-se que o modelo de avaliação do conforto térmico e o questionário subjetivo desenvolvido pelos autores Batiz e Goedert são instrumentos valiosos para entender cada vez mais esse processo tão complexo. Houve coincidência superior a 90\% entre os resultados do PMV e PPD calculados pelas expressões de Fanger e as respostas dos alunos. Foi verificado na pesquisa que existe uma relação direta entre a atenção e a memória e os valores de PMV. Quando os valores de PMV se encontram próximos do valor neutro (conforto), a atenção e a memória permanecem inalteradas. Então se pôde apurar que na condição neutra os alunos apresentam bom desempenho. Obteve-se média de desempenho de $70 \%$ nos testes de atenção e memória e na aplicação das figuras complexas de Rey.

\section{Artigo recebido em 05/02/2009 Aprovado para publicação em 28/06/2009}

\section{REFERÊNCIAS}

American Society of Heating and Air Conditioning Engineers - ASHRAE. Physiological principles for comfort and health. In: Handbook Fundamentals. Atlanta, 2001. p. $8.1-8.2$.

BATIZ, E. C.; GOEDERT, J. Avaliação do Conforto Térmico em Postos de Trabalho de Motoristas de Ônibus: Estudo de Caso. In: CONGRESSO BRASILEIRO DE ERGONOMIA, 14, 2006, Curitiba. Anais... Curitiba: ABERGO, 2006. ISBN: 85-89211-06-1

CAMPOS, J. A. A.; SANTACANA, M. F.; NEBOT, T. K. Repertorios cognoscitivos de atención, percepción y Memoria. Documento de trabajo. Barcelona, España: Departamento de Personalidad, Evaluación y Tratamiento Psicológico, Facultad de Psicología, Universidad deBarcelona, s/d. Disponívelem:<http://diposit. ub.edu/dspace/bitstream/2445/345/1/144. pdf>. Acesso em: 23 dezembro 2008.

FANGER, P. O. Thermal comfort: analysis and applications in environmental engineering. United States: McGraw-Hill Book Company, 1970. $244 \mathrm{p}$.
GOEDERT, J.; BATIZ, E. C. Aspectos para Discussão de uma Proposta para Avaliação de Conforto Térmico em Postos de Motorista de Ônibus. São Paulo: SAE, 2004.

GOUVÊA, T. C. et al. Avaliação do Conforto Térmico: Uma Experiência de Campo. In: ENCONTRO NACIONAL SOBRE CONFORTO NO AMBIENTE CONSTRUÍDO (ENCAC), 7, e CONFERÊNCIA LATINO-AMERICANA SOBRE CONFORTO E DESEMPENHO ENERGÉTICO DE EDIFICAÇÕES (COTEDI), 2, 2003, Curitiba. Anais...

HOWELL, W.; STRAMLER, C. S. The Contribution of Psychological Variables to the Prediction of Thermal Comfort Judgments in Real World Settings. ASHRAE Transactions, v. 87, n. 1, p. 609-621, 1981.

INTERNATIONAL ORGANIZATION FOR STANDARDIZATION. ISO7726: Thermal Environment - Instruments and method for measuring physical quantities. Geneva, 1998.
L ISO7730: Moderate Thermal Environments - Determination of the PMV and PPD indices and specification of the conditions for thermal comfort. Geneva, 1994.

ISO7730: Ergonomics of the thermal environment - Analytical determination and interpretation of thermal comfort using calculation of the PMV and PPD indices and local thermal comfort criteria. Geneva, 2005.

ISO10551: Ergonomics of the Thermal Environment - Assessment of the influence of the Thermal Environment Using Subjective Judgment Scales. Geneva, 1995.

LAMBERTS, R.; XAVIER, A. A. P. Conforto térmico em ambientes internos. Florianópolis: Laboratório de Eficiência Energética em Edificações, 2003. (Material didático para disciplina conforto térmico). Disponível em: <http:// teses.eps.ufsc.br/Resumo.asp?1250>. Acesso em: 01 setembro 2006. 
MENDELL, M. J.; HEATH, G. A. Do indoor pollutants and thermal conditions in schools influence student performance? A critical review of the literature. Indoor Air, v. 15, p. 27-52, 2005

REY, A. Teste de cópia e de reprodução de memória de figuras geométricas complexas. Tradução de Teresinha Rey e Lucia C. F. Franco. São Paulo: Casa do Psicólogo, 1999.

RODRIGUEZ, A.; DELGADO, A. El método y las técnicas en Psicología del Trabajo y de las organizaciones. In: RODRIGUEZ, A. Introducción a la Psicología del trabajo y de las Organizaciones. Madrid: Pirámide, 1998. p. 71-84.
SANTOS, T. M. Manual de Psicologia. 2 ed. São Paulo: Editora Nacional, 1967.

SILVA, L. B. Análise da relação entre Produtividade e conforto térmico: o caso dos digitadores do centro de processamento de dados da Caixa Econômica Federal de Pernambuco. Florianópolis, 2001. Tese (Doutorado em Engenharia de Produção) - Universidade Federal de Santa Catarina.

STEFANO, P. C. et al. Thermal comfort in Italian classrooms under free running conditions during mid seasons: Assessment through objective and subjective approaches. Building and Environment, 2008. Doi:10.1016/j. buildenv.2008.05.23.
WARGOCKI, P. et al. The effects of classroom air temperature and outdoor air supply rate on performance of school work by children. Proceedings of Indoor Air I, v. 1, p. 368-72, 2005.

WOODS, J. E. et al. Relationships between measures of Thermal Environment and measures of Worker Productivity. ASHRAE Transactions, v. 87, n. 2, p. 117-144, 1981.

XAVIER, A. A. de P. Condições de conforto térmico para estudantes de $2^{\circ}$ Grau na região de Florianópolis. Florianópolis, 1999. 198 p. Dissertação (Mestrado em Engenharia de Produção) - Universidade Federal de Santa Catarina.

\section{SOBRE OS AUTORES}

Prof. Eduardo Concepción Batiz, Eng. Dr.

Sociedade Educacional de Santa Catarina (SOCIESC) Instituto Superior Tupy (IST)

Joinville - SC, Brasil

E-mail: eduardo.batiz@sociesc.org.br

\section{Jean Goedert, MSc.}

Sociedade Educacional de Santa Catarina (SOCIESC) Instituto Superior Tupy (IST)

Joinville - SC, Brasil

E-mail: jean_goedert@busscar.com.br

Junir Junior Morsch, Tecgo.

Sociedade Educacional de Santa Catarina (SOCIESC)

Instituto Superior Tupy (IST)

Joinville - SC, Brasil

E-mail: junirm@hotmail.com

Pedro Kasmirski Junior, Tecgo.

Sociedade Educacional de Santa Catarina (SOCIESC) Instituto Superior Tupy (IST)

Joinville - SC, Brasil

E-mail: jr.kasmirski@ibest.com.br

Rafael Venske, Tecgo.

Sociedade Educacional de Santa Catarina (SOCIESC) Instituto Superior Tupy (IST)

Joinville - SC, Brasil

E-mail: ravenske@ibest.com.br 